\title{
Um estudo de caso sobre os impactos ambientais na produção do jeans em uma empresa de Jaraguá do Sul (SC)
}

\section{A case study about environmental impacts on the production of jeans in a company in Jaraguá do Sul (BR)}

Vivian Andreatta Los ${ }^{[1]}$, Mariana Luísa Schaeffer Brilhante $^{[2]}$, Valdecir Babinski Júnior ${ }^{[3]}$, Lucimeri Sabin Ferreira $^{[4]}$, Lisnara de Araújo Chrischansky ${ }^{[5]}$, Caroline de Almeida $^{[6]}$, Lorruama Maluara Chiari Carrança ${ }^{[7]}$

[1] Mestra em Educação, FURB. vlos@ifsc.edu.br

[2] Mestranda em Design de Vestuário e Moda, UDESC. marsbxx@gmail.com

[3] Mestre em Design de Vestuário e Moda, UDESC.vj.babinski@gmail.com

[4] Pós-graduada em Interdisciplinariedade na Prática

Pedagógica, FURB. lucimeri.sabin@hotmail.com

[5] Estudante do Curso Técnico Integrado em Modelagem do Vestuário, IFSC.lisaraujo487@icloud.com

[6] Estudante do Curso Técnico Integrado em Modelagem do Vestuário, IFSC.loohh.maa@gmail.com

[7] Estudante do Curso Técnico Integrado em Modelagem do Vestuário, IFSC. carolinealmeida0402@gmail.com 
Resumo: o presente artigo teve o intuito de verificar, localmente, como ocorre a produção do jeans no contexto de uma indústria têxtil e de confecção. Para tanto, selecionou-se o caso de uma empresa de Jaraguá do Sul (SC). A coleta de dados ocorreu por intermédio de uma palestra de um dos colaboradores da empresa. A partir disso, essa pesquisa não verificou in loco se a empresa possui métodos sustentáveis na produção do material, pois não se teve acesso ao seu parque fabril. Assim, o afirmado pelo palestrante não pode ser confirmado na prática. De todo modo, ainda que limitada por desvios, a presente pesquisa pode servir de modelo para subsidiar futuras entrevistas com indústrias do segmento jeans.

Palavras-chaves: Indústria do Jeans. Impactos ambientais. Sustentabilidade.

Abstract: this article aimed to verify, locally, how jeans are produced in the context of a textile and apparel industry. Therefore, the case of a company from Jaraguá do Sul (SC) was selected. Data collection took place through a lecture by one of the company's employees. From this, this research did not verify in loco whether the company has sustainable methods in the production of the material, as it did not have access to its industrial park. Thus, what was stated by the speaker cannot be confirmed in practice. Anyway, although limited by deviations, this research can serve as a model to support future interviews with industries in the jeans segment.

Keywords: Jeans industry. Environmental impacts. Sustainability.

\section{INTRODUÇÃO}

Os produtos consumidos cotidianamente demoram até se decompor no planeta. Em geral, o plástico leva 400 anos para se degradar, o vidro leva mais de 1.000 anos, o alumínio mais de 200 anos e a borracha não possui um tempo determinado (MINISTÉRIO DO MEIO AMBIENTE, 2005). Ademais, muitos alimentos vêm de áreas de desmatamento e de exploração animal, o que torna o consumo uma preocupação moderna na perspectiva da sustentabilidade.

De acordo com Morita (2013), os impactos ambientais causados pelas indústrias têxteis e de confecção apresentam-se como preocupações sociais, principalmente com relação ao consumo de água. Para a autora, o uso de agrotóxicos na transformação de matérias-primas e o emprego de produtos químicos para o tingimento podem ser responsáveis pela emissão de poluentes que afetam a água, o solo e o ar. Alguns problemas ambientais que existem atualmente, como mudanças climáticas e a redução da camada de ozônio, podem ser exemplos de como a vida humana sofre a influência dos impactos dessas indústrias. 
Toniollo, Zancan e Wüst (2015) indicam mensurar esses impactos a partir do montante de processos industriais e da quantidade de resíduos gerados em cada uma de suas etapas. Conforme sinalizam os autores, a NBR 10.004/2004 sugere que, se os resíduos sólidos têxteis não forem tratados da forma ambientalmente correta, há incremento no risco de mortalidade de seres humanos, animais e ecossistemas ligados direta ou indiretamente com as indústrias têxteis e de confecção. Ademais, em geral, esses resíduos possuem como características: (I) inflamabilidade; (II) corrosão; (III) toxicidade; e (IV) potencial patogênico.

De acordo com Avila (2019), faz-se possível entender que as consequências geradas pela formação de resíduos sólidos têxteis implicam na inalterabilidade entre a regeneração e a utilização dos recursos advindos da natureza. A autora reforça essa problemática, não só com base no fato de que os artigos de moda podem ser produzidos de maneira a serem descartados com um curto período de uso, mas também de que se utilizam quantidades consideráveis de materiais e de energia para providenciá-los.

Conforme a perspectiva de Salcedo (2014), a consequência danosa ocasionada pelos resíduos sólidos têxteis pode ser observada nas etapas de produção da fibra, do tecido, no design, durante o uso e no decorrer da manutenção. A autora ainda afirma que, se os produtos têxteis forem descartados de maneira incorreta, podem ser acrescidos como significativos na formação de resíduos sólidos têxteis.

Santos (1997) diz que, quando as empresas se propõem a reduzir os impactos durante a produção, os custos ambientais podem ser minimizados ou até mesmo eliminados. Para que a produção seja ecologicamente correta faz-se necessário que se tenham princípios de pesquisa e inovação no processo de produção, a exemplo da produção de fibras para confecção de tecidos a partir da reciclagem de PET (VEZZÁ; COTAIT; ALVES, 2006) ou com a utilização de corantes naturais como uma alternativa sustentável (NARIMATSU et al., 2020). Nessa pers- 
pectiva, Santos (1997) menciona que, para que os processos industriais atendam requisitos pró-sustentabilidade, deve-se ter atenção às seguintes dimensões: (I) água; (II) ar; e (III) terra.

No âmbito da dimensão da água, Santos (1997) observa que a mesma consiste em um dos elementos mais relevantes para a produção de peças de vestuário. A autora esclarece que, no caso do jeans, o processo de beneficiamento da maIha de algodão considera o tingimento como fator de qualidade. Essa qualidade sofre uma variação conforme os produtos químicos utilizados, tais como corantes que possuem poluentes tóxicos. Santos (1997) acrescenta que a estação para o tratamento de água pode ser uma opção a ser considerada para que a água não volte poluída para a fonte de onde foi captada.

Quanto à dimensão do ar, Santos (1997) orienta que se deve manter a qualidade do ar no entorno do parque fabril destinado à produção têxtil e de vestuário. A autora acredita que problemas respiratórios podem ter origem nos gases emitidos pelas chaminés durante o processo de produção nessas fábricas. Nesse sentido, Santos (1997) recomenda o emprego de filtros e equipamentos especiais para a redução da emissão de gases poluentes.

Por último, no tocante à terra, Santos (1997) afirma que a qualidade do solo sofre alteração por conta dos resíduos sólidos têxteis e a filtragem de água quimicamente contaminada. Nessas situações, a autora cita que as estações de tratamento de água podem ser eficazes e que se faz interessante produzir um estudo de solo no terreno no qual a empresa encontra-se fixada.

Além disso, Santos (1997) também aponta para a problemática do algodão. O algodão consiste na principal matéria-prima para a produção do jeans. Faz-se importante que a empresa esteja atenta quanto a origem da fibra e quanto à forma que ela foi plantada, nutrida, cultivada e colhida (SANTOS, 1997). Além da rastreabilidade no plantio do algodão, a autora sugere que sejam estabelecidas medidas para assegurar aos produtores seus direitos trabalhistas. 
Diante do exposto até o momento, o presente artigo possui como objetivo verificar, localmente, como ocorre a produção do jeans no contexto de uma indústria têxtil e de confecção. Para essa finalidade, elegeu-se a empresa $A^{[8]}$, localizada em Jaraguá do Sul (SC), nos arredores do bairro Barra do Rio Cerro. Como critério de escolha da empresa, levou-se em consideração o fato de que a mesma autoproclama-se sustentável quanto à produção do jeans.

Por fim, ressalta-se que essa pesquisa está estruturada a partir de uma revisão bibliográfica sobre a produção do jeans, com ênfase em requisitos pró-sustentabilidade. Após, procede-se para os aspectos metodológicos, para a discussão dos resultados obtidos e para as considerações finais.

\section{PRODUÇÃO DO JEANS}

Levi Strauss chegou aos Estados Unidos da América em um momento em que exploradores partiram para a Califórnia em busca de ouro. Strauss trabalhava como vendedor ambulante e percebeu que os garimpeiros necessitavam de roupas resistentes às atividades desempenhadas, que fossem produzidas com um tecido grosso e escuro. Dessa maneira, Strauss confeccionou calças reforçadas com lonas e, assim, surgiu o primeiro jeans, em 1850 (FIGUEIREDO; CAVALCANTE, 2010).

No ano de 1856, com a inauguração de sua primeira fábrica, a Levi Strauss \& Co., houve a substituição de lona por algodão. Tratava-se de um tecido mais macio, produzido na França e que recebeu o nome de denim. Na primeira metade do século XIX, as peças produzidas com o novo tecido se estabeleceram no mercado e passaram a representar, também, um símbolo de rebeldia relacionado com a juventude. Nos anos 1990, as peças de jeans passaram a ser consideradas multifuncionais, práticas e democráticas. A tendência fever jeans (febre do jeans), no final da década, colaborou para solidificar a presença desse item no guarda-roupa do século XX (FIGUEIREDO; CAVALCANTE, 2010).
[8] Nome fictício designado para a empresa investigada com a finalidade de resguardar seu anonimato. 
Importa destacar que o termo jeans se refere ao tecido lavado que já recebeu algum beneficiamento têxtil, como tratamentos de superfície, enquanto o termo denim pode ser empregado para representar o tecido cru, sem tingimentos ou intervenções (DIAS, 2015). Conforme Figueiredo e Cavalcante (2010), o termo Denim Índigo Blue refere-se ao nome utilizado mundialmente para o tecido jeans.

Figueiredo e Cavalcante (2010) apontam que, usualmente, faz-se o uso do fio $100 \%$ algodão para a produção desse tecido. O processo baseia-se na construção de dois fios, um de trama de algodão cru e um de urdume tingido índigo. No entanto, a composição do material também pode ser feita com lycra e outros fios mais resistentes ${ }^{[9]}$ e elásticos para formar um tecido plano.

Ao estudar a obra de Sabino (2006), Figueiredo e Cavalcante (2010) citam que, após ser feito o trabalho de fios, o denim torna-se tecido e, em seguida, pode ser colocado em rolos com mais de 70 metros de comprimento. Esses rolos são vendidos para as fábricas, onde serão acondicionados, enfestados e cortados para se transformar em peças jeans.

De acordo com Augusto (2017), as etapas do processo de desenvolvimento da peça jeans envolvem: (I) criação; (II) modelagem; (III) risco; (IV) corte; (V) costura; (VI) beneficiamento; e (VII) acabamento.

O setor de criação e desenvolvimento de produto possui a responsabilidade pela definição total do produto, que fica representada pelo desenho em ficha técnica. Nessa etapa, o estilista faz a definição da escolha do tecido, o que envolve a composição da fibra e o nível de intensidade do tingimento. Todos esses aspectos são definidos durante as pesquisas de tendências (AUGUSTO, 2017).

Em seguida, o desenho parte para a próxima etapa, a modelagem. A criação passa pela interpretação do modelista, para que possa haver o desenvolvimento das bases e impedir que a vestibilidade da peça final seja comprometida (AUGUSTO, 2017). Posteriormente, a peça segue para a fase do risco,
[9] Exemplo: viscose, modal e tencel (DIVYA; MANONMANI; JAYAKUMARI, 2018). 
que dará origem à folha riscada com os moldes para corte, que pode ser feito manualmente, em papel, ou computadorizado, com a utilização de um software (AUGUSTO, 2017).

$\mathrm{Na}$ fase de corte, os moldes são cortados em conformidade com a estruturação estabelecida pelo programa, processo que pode ser efetuado manualmente ou por meio de equipamento especializado (AUGUSTO, 2017). Salcedo (2014) afirma que essa etapa pode ser considerada uma das maiores responsáveis pela geração de resíduos sólidos têxteis.

Seguidamente, as peças são costuradas. Nessa etapa, precisa-se de todo o detalhamento para a sua confecção e atenção com a matéria-prima, para que o tecido tenha um bom caimento (AUGUSTO, 2017). Salcedo (2014) alerta que, nesse processo, também existe a geração de resíduos.

$\mathrm{O}$ procedimento de beneficiamento possui grande relevância no sentido de possibilitar a diferenciação e a originalidade da peça. Como consequência, foram criadas operações para transmitir o aspecto desejado na mesma. Esses aspectos buscam imitar a aparência de rasgado, envelhecido, gasto, empoeirado, camuflado, sujo, entre outros. Alguns processos de lavagem executados no beneficiamento são: délavé, destroyed, estonagem e desgaste localizado. No âmbito de impactos ambientais, o solo e a água são afetados com a liberação de poluentes (AUGUSTO, 2017).

No processo de acabamento, são empregados os botões, etiquetas e outros aviamentos necessários. Para completar a finalização, realiza-se a remoção de fiapos ou rebarbas que permaneceram na costura e, dessa forma, finaliza-se a sequência de desenvolvimento (AUGUSTO, 2017).

Figueiredo e Cavalcante (2010) mencionam que o Brasil faz parte dos principais produtores desse tecido no mundo, com uma capacidade instalada de produção acima de $600 \mathrm{mi}-$ Ihões de metros lineares por ano. Um estudo realizado pelo Instituto de Estudos e Marketing Industrial (IEMI, 2013), que avaliou o jeans produzido no país entre os anos de 2008 e 2012, evidenciou que sua fabricação apresentou um cresci- 
mento na quantidade de peças geradas, com uma periodicidade superior a $6 \%$ ao ano. Para materializar o montante, em 2012 foram produzidas 349,8 milhões de peças jeans, um aumento de $27 \%$ se comparado a 2008.

Duarte (2013) aponta para a centralidade do jeans na cultura material que, somada à sua produção, destinada a suprir demandas mundiais de vestuário, resulta em um problema de produtividade e faz com que a indústria têxtil e de confecção enfrente condições desafiadoras no campo da qualidade e sustentabilidade. Essa demanda também consiste em uma preocupação na visão de Duarte (2013, p. 25), visto que o algodão - principal fibra do jeans - resulta em $80 \%$ do mercado global de têxteis: "[...] as fibras de algodão, são provenientes de plantações que ocupam uma área de 3\% do globo terrestre e que empregam 40 milhões de pessoas, em péssimas condições de trabalho, de extrema pobreza e insalubridade". Corroboram ao exposto Mello e César (2020, p. 360), quando afirmam que o Brasil se destaca nos setores da cadeia têxtil e de confecção de couro, jeans, calçados e componentes de calçados, "[...] movimentando mais de US\$ 90 bilhões em faturamento". Segundo a Associação Brasileira da Indústria Têxtil e de Confecção (ABIT, 2020), o Brasil é o quarto maior produtor e consumidor de denim do mundo. A seguir, discorre-se sobre os requisitos para a sustentabilidade na produção do jeans.

\subsection{REQUISITOS PARA A SUSTENTABILIDADE NA PRODUÇÃO DO JEANS}

De acordo com Estender e Pitta (2008), o conceito de desenvolvimento sustentável surgiu durante a Comissão de Brundtland, realizada na Noruega, na década de 1980. À época, a primeira-ministra norueguesa, Gro Harlem Brundtland, expôs a seguinte definição para o termo: "É a forma como as atuais gerações satisfazem as suas necessidades sem, no entanto, comprometer a capacidade de gerações futuras satisfazerem as suas próprias necessidades" (BRUNDTLAND, 1991, p. 46). 
Estender e Pitta (2008) afirmam que a sustentabilidade deve atender a três fatores simultaneamente: (I) econômico; (II) social; e (III) ambiental. Os autores compreendem que esse conceito está relacionado com a proposição do triple bottom line (tripé da sustentabilidade, em livre tradução) de John Elkington na década de 1990. Estender e Pitta (2008, p. 22) comentam que "Muitas empresas aderiram a esse conceito, pois acreditavam que esse era um desafio de 'esverdeamento' dos negócios, tornando-os mais eficientes e reduzindo custos". Schulte (2011, p. 53) afirma que "[...] o que importa é a satisfação pessoal imediata dos indivíduos, sem considerarem o impacto social ou ambiental das suas ações para satisfazer os desejos hedonistas. Essa forma inconsequente de agir tem contribuído para o atual cenário de desenvolvimento humano insustentável".

Ao explorar o fator econômico, Estender e Pitta (2008) expõem que, ao levar em consideração o desenvolvimento sustentável, será necessário introduzir na ideia de capital econômico os conceitos de capital humano e intelectual, que passam a ser fundamentais para a análise desse pilar. De modo similar, Elkington (1999) justifica a existência de duas formas de capital natural: o capital natural crítico, que representa a essencialidade para a continuidade do equilíbrio natural; e o capital natural renovável, que refere-se aos recursos renováveis.

Quanto ao fator social, Estender e Pitta (2008) acreditam que a desigualdade social não faz parte do conceito de sustentabilidade. Com isso, se o sistema social não estiver equilibrado, a progressão conjunta desses princípios se torna inviável. Fukuyama (1995, p. 34) alega que "[...] o capital social é uma capacidade que surge da prevalência da confiança em uma sociedade ou em partes dela". E a "[...] capacidade de as pessoas trabalharem juntas, em grupos ou organizações, para um objetivo comum".

Estender e Pitta (2008) explicitam que o fator ambiental leva as empresas a avaliarem se são ambientalmente susten- 
táveis. Para isso, faz-se necessário identificar se o equilíbrio da natureza é cuidado de maneira significativa. De maneira similar, Santos e Silva (2018, p. 106) afirmam que:

A contribuição da sustentabilidade para a competitividade empresarial pode ser associada à capacidade de ela atender a fatores que são primordiais para o aumento do potencial competitivo, tais como: eficiência nos processos, uso de novas tecnologias nos processos e produtos, capacitação dos recursos humanos e desenvolvimento social.

Estender e Pitta (2008) declaram que as empresas devem conduzir a maneira que esses pilares serão colocados em prática, para que possam estar inseridas dentro do padrão ambientalmente correto.

Expostas as perspectivas acerca do desenvolvimento sustentável, Augusto (2017) entende que o impacto causado pela indústria de produção do jeans interfere no equilíbrio entre a regeneração e utilização dos recursos naturais. Esse impacto pode ser observado em quase todas as etapas da produção de um artigo de moda: produção da fibra, produção do tecido, design, produção da peça de roupa e durante o período de uso.

Salcedo (2014) diz que, durante o cultivo, existe um comprometimento da fertilidade da terra, contaminação da cadeia alimentar e um possível prejuízo à saúde das pessoas que têm contato direto com os agrotóxicos utilizados.

Durante o processo de tingimento do jeans, Gorini (1999) relata que, pelo fato do índigo (corante utilizado para tingir) não ser o mais indicado para o algodão, ele possui uma certa resistência para fixar ao tecido e, dessa forma, faz-se necessário refazer o banho e a oxidação diversas vezes. Além disso, os corantes indigóides (substância química utilizada no processo de tingimento) possuem uma estrutura molecular complexa, o que os torna mais estáveis quimicamente e mais vigorosos ao processo de remoção feito para o tratamento de efluentes.

Augusto (2017) acredita que a indústria têxtil tem aspectos que precisam ser remodelados para que possa ser leva- 
da em consideração no âmbito sustentável. Principalmente no que se diz respeito ao consumo de energia, emissões de gases, uso de químicos, descarte de resíduos, condições de trabalho e consumo de água.

Maneiras de minimizar grande parte dos problemas já são estudados há algum tempo e Santos (1997) destaca uma empresa catarinense que já adotou tais métodos para uma indústria ecologicamente correta. A autora comenta que a preocupação das empresas na adoção desses métodos conscientes se dá, geralmente, para obter os selos verdes em seu produto e atrair mais a atenção dos consumidores. Em estágios de empresas que adotam sistemas de gestão ambiental, tem como objetivo conseguir a certificação ISO 14.000. Pode-se perceber grande avanço na busca de respostas e melhorias para esses problemas.

Santos e Silva (2018, p. 105) abordam que as questões sustentáveis passaram a "[...] ser discutidas também no âmbito empresarial, tornando-se praticamente obrigatória nas grandes organizações devido ao crescente número de regulamentações que começaram a ser criadas [...]". Isso mostra o crescente aumento de ações sustentáveis em empresas do setor têxtil e de confecção do vestuário.

José et al. (2014) explicam que, para obter a certificação do ISO 14.000/14.001, as empresas e indústrias devem passar por auditorias que deverão ser realizadas periodicamente, e essas auditorias também devem ser realizadas por outras empresas que tenham a certificação do ISO, sendo, ainda, reconhecida e credenciada pelo INMETRO. Os seguintes requisitos são exigidos:

- Cumprimento da legislação ambiental;

- Diagnóstico atualizado dos aspectos e impactos ambientais de cada atividade;

- Procedimentos padrões e planos de ação para eliminar ou diminuir os impactos ambientais. 
Desse modo, percebe-se a importância da implantação de práticas inovadoras sustentáveis no mercado têxtil, que podem resultar em melhorias econômicas, ambientais e sociais, que trazem benefícios para a empresa, consumidor e sociedade. A seguir, apresentam-se os procedimentos metodológicos dessa pesquisa.

\section{PROCEDIMENTOS METODOLÓGICOS}

Acerca dos aspectos metodológicos, o presente artigo visou obter dados mediante a realização de um estudo de caso com abordagem descritiva e qualitativa para a análise de resultados. De acordo com Goldenberg (2004), o estudo de caso se trata de uma análise aprofundada de um caso individual e os resultados são obtidos por meio da investigação feita de maneira pontual e intensa de uma única situação.

Goldenberg (2004) define o método qualitativo como a não especificação de quantidade de amostragem, e busca evidenciar conhecimentos que podem ser comprovados por meio da compreensão de um grupo ou de uma organização. Ainda, segundo o autor, a opinião ou crença do pesquisador não deve ser transmitida para a pesquisa.

A coleta de dados foi realizada por meio de uma palestra que um colaborador enviou aos autores desse artigo e que responde todas as pautas abaixo (Quadro 1). A palestra foi enviada em 16 de junho de 2021, mas a mesma foi publicada em uma rede social de vídeos em 8 de junho de 2021, com o objetivo de verificar como ocorre a produção do jeans no contexto da indústria.

Quadro 1: Pautas selecionadas para a entrevista

\begin{tabular}{|l|l|l|}
\hline Pautas & Objetivo & Embasamento \\
\hline $\begin{array}{l}\text { 1. Como ocorre a } \\
\text { produção do jeans } \\
\text { na empresa? }\end{array}$ & $\begin{array}{l}\text { Estabelecer o processo } \\
\text { produtivo e buscar } \\
\text { evidências de aspectos } \\
\text { sustentáveis }\end{array}$ & Augusto (2017). \\
\hline
\end{tabular}




\begin{tabular}{|l|l|l}
\hline Pautas & Objetivo & Embasamento \\
\hline $\begin{array}{l}\text { 2. Quais requisitos } \\
\text { são empregados no } \\
\text { processo produtivo } \\
\text { do jeans sustentável? }\end{array}$ & $\begin{array}{l}\text { Compreender se os } \\
\text { requisitos estabelecidos } \\
\text { na literatura se } \\
\text { confirmam no estudo } \\
\text { de caso (consumo de } \\
\text { energia, emissões de } \\
\text { gases, entre outros) }\end{array}$ & $\begin{array}{l}\text { Estender e } \\
\text { Pitta (2008) e } \\
\text { Augusto (2017). }\end{array}$ \\
$\begin{array}{l}\text { 3. Quais certificações } \\
\text { ou planos de ação a } \\
\text { empresa emprega } \\
\text { nesse processo e } \\
\text { como os impactos } \\
\text { ambientais são } \\
\text { mensurados? }\end{array}$ & $\begin{array}{l}\text { Averiguar a } \\
\text { conformidade do } \\
\text { processo produtivo } \\
\text { aos pressupostos das } \\
\text { certificações e dos } \\
\text { planos de ação, de } \\
\text { modo a entender }\end{array}$ & $\begin{array}{l}\text { Santos (1997) e } \\
\text { como a empresa } \\
\text { mensura o impacto } \\
\text { ambiental produzido }\end{array}$ \\
\hline
\end{tabular}

Fonte: elaborado pelos autores (2021).

No Quadro 1 observa-se que as pautas foram estabelecidas sob o formato de perguntas e que o embasamento está articulado aos pressupostos teóricos levantados no referencial teórico. Para a análise das respostas obtidas, seguiu-se uma postura interpretativista, em termos de epistemologia e, na transcrição do áudio da palestra, foi empregado o uso do software Amberscript. Assim, foram estabelecidas três categorias - processo produtivo do jeans, atendimento aos requisitos pró-sustentabilidade e impactos ambientais - para a discussão dos resultados, conforme explorado no tópico a seguir.

\section{RESULTADOS E DISCUSSÕES}

A partir da palestra observada, percebeu-se que as categorias estabelecidas foram ora refutadas e ora corroboradas diante da literatura científica utilizada para a construção do corpo de conhecimento dessa pesquisa. Isso ocorreu frente às categorias estabelecidas para análise. 
Acerca da primeira categoria, processo produtivo do jeans, o palestrante mencionou que: "tudo inicia com uma pesquisa, envolvendo a escolha da matéria-prima. A prova de modelagem, passa pela lavanderia 5.0, que é representada pelos processos de e-flow, ozônio e laser, onde a peça é cortada e lavada e, em seguida, passa para a costura [...]". Isso vai ao encontro do argumento de Augusto (2017), que sustenta que o processo de produção do vestuário envolve as fases de criação, modelagem, risco, corte, costura, beneficiamento e acabamento. Algumas diferenças no processo de produção, como por exemplo a lavagem ser realizada antes da costura, podem ser resultados do tipo de lavanderia existente na empresa.

Quanto ao estabelecido para a segunda categoria de análise, atendimento aos requisitos pró-sustentabilidade, percebeu-se que a empresa pesquisada cumpre com os três requisitos sustentáveis mediante o estabelecido por Estender e Pitta (2008). Isso pode ser evidenciado na fala do palestrante: "estamos vendendo as nossas calças jeans sem repassar os preços dos custos", e deixa claro que "é possível fazer de uma maneira mais sustentável e permanecer com os mesmos valores". Esse cuidado com o fornecimento de vestuário sustentável com preços acessíveis é bem-vindo dentro do sistema pró-sustentabilidade.

Apesar da declaração do palestrante, importa manifestar que os autores dessa pesquisa não obtiveram acesso às instalações da empresa A para verificação e coleta de dados no local. Portanto, ainda que haja indícios do respeito da empresa aos fatores econômicos, sociais e ambientais, não houve produção de dados concretos nessa pesquisa.

A terceira categoria estabelecida para a análise, impactos ambientais, permite compreender que a empresa mensura o impacto ambiental produzido por sua atividade econômica com base na busca pelo selo verde. O palestrante corrobora o argumento ao denotar que:

Temos um sistema que mede o impacto ambiental. Esse sistema é adaptado à nossa lavanderia e ele consegue medir se estamos tendo baixo, médio ou alto impacto 
ambiental. Todas as nossas peças possuem um selo verde, que significa baixo impacto ambiental, que a gente não usa produtos químicos nocivos, usamos apenas químicos sustentáveis. É um software pago para uma empresa que nos permite medir o impacto causado no consumo de água, energia, químicos e mão de obra na produção do jeans. Em todas as nossas peças é possível encontrar o selo de jeans mais sustentável do Brasil. Nós falamos que são os jeans mais sustentáveis do Brasil porque a gente sabe que muitas marcas trabalham com linhas de produtos sustentáveis, mas nós da empresa A oferecemos $100 \%$ das nossas coleções feitas dessa maneira 100\% sustentável.

Frente ao exposto pelo palestrante, sublinha-se que esta pesquisa não verificou in loco se o afirmado pode ser confirmado na prática. Santos (1997) destaca que a busca pelos métodos conscientes visa atrair a atenção dos consumidores e melhorar a visão da empresa frente às questões ambientais. Santos e Silva $(2018$, p. 104) afirmam que "[...] a sustentabilidade pode proporcionar melhorias significativas nos âmbitos econômico, social e ambiental, e a inovação pode impulsionar o desenvolvimento de novas estratégias, produtos, processos e sistemas de produção que melhorem o desempenho corporativo". A partir dos resultados alcançados mediante as informações coletadas no vídeo do palestrante, desenvolveu-se o Quadro 2.

Quadro 2: Resultados mediante as categorias

\begin{tabular}{|l|l|l|}
\hline Categoria & Análise & Argumento \\
\hline $\begin{array}{l}\text { Processo } \\
\text { produtivo } \\
\text { do jeans }\end{array}$ & Corroborado & $\begin{array}{l}\text { A empresa A transforma } \\
\text { o denim em jeans a } \\
\text { partir de processos } \\
\text { produtivos industriais }\end{array}$ \\
\hline
\end{tabular}




\begin{tabular}{|l|l|l|}
\hline Categoria & Análise & Argumento \\
\hline $\begin{array}{l}\text { Atendimento aos } \\
\text { requisitos pró- } \\
\text { sustentabilidade }\end{array}$ & $\begin{array}{l}\text { Corroborado } \\
\text { parcialmente }\end{array}$ & $\begin{array}{l}\text { Apesar de citado pelo } \\
\text { palestrante, a informação } \\
\text { sobre a certificação verde da } \\
\text { empresa A não foi confirmada } \\
\text { por meio de dados colhidos } \\
\text { ou observados in loco }\end{array}$ \\
\hline $\begin{array}{l}\text { Impactos } \\
\text { ambientais }\end{array}$ & $\begin{array}{l}\text { Corroborado } \\
\text { totalmente }\end{array}$ & $\begin{array}{l}\text { O palestrante declara que } \\
\text { a empresa A faz uso de um } \\
\text { software para mensurar } \\
\text { seus impactos ambientais }\end{array}$ \\
\hline
\end{tabular}

Fonte: elaborado pelos autores (2021).

O Quadro 2 sintetiza a discussão realizada. Novamente, os autores da pesquisa frisam que não foram coletados dados diretamente da empresa, ou seja, in loco, ainda que tentativas tenham sido realizadas ao longo de dois meses. Ademais, acredita-se que a palestra esteja imbuída de objetivos diferentes daqueles estimados para as perguntas elaboradas na pesquisa. Explorados os resultados, procede-se para as considerações finais do capítulo. Em uma pesquisa paralela, verificou-se, no site da empresa A, que a mesma busca estimular os seus fornecedores de matérias-primas - como o jeans - a usarem as fibras de poliéster de garrafa PET, entre outros tecidos e aviamentos sustentáveis. Também está expresso nesse site que a empresa A realiza palestras de conscientização e informações sobre os métodos sustentáveis para seus fornecedores e colaboradores.

\section{CONSIDERAÇÕES FINAIS}

Esse artigo teve como objetivo verificar, localmente, como ocorre a produção do jeans no contexto de uma indústria têxtil e de confecção. Foi evidenciado, nessa pesquisa, que a empresa A não cumpre totalmente com todos os requisitos estipulados nas categorias de análise que foram propostos na 
pesquisa. Porém, percebe-se que essa defasagem de dados, devido à impossibilidade de realização da visita in loco e/ou entrevista, prejudicou a identificação da realidade ocorrida dentro da empresa estudada. Além disso, ela afirma ter uma cultura de aplicação da sustentabilidade tanto na perspectiva ambiental, como na perspectiva econômica e, como resultado, ressalta-se que não foram verificadas evidências práticas sustentáveis com benefícios diretos para a empresa e o meio ambiente, apesar de em seu site haver comentários e relatórios sobre alguns avanços nessa área; além de uma forte tendência à disseminação de conhecimentos sobre procedimentos pró-sustentáveis a seus colaboradores e fornecedores.

Houve limitações para realização da entrevista planejada. Inicialmente, essa entrevista seria com um gerente de setor ou encarregado, todavia, não houve receptividade por parte da empresa A, ainda que os autores insistissem. Assim, os dados foram obtidos por intermédio de uma palestra, o que pode ter provocado distorções na intenção dos objetivos traçados para as perguntas estipuladas. Assim, estima-se que as dúvidas dos autores não foram sanadas totalmente.

Para futuros estudos e para a formação de uma agenda acerca do assunto, sugere-se que as pautas e perguntas estipuladas nessa pesquisa sejam, factualmente, aplicadas no contexto de uma empresa na cidade de Jaraguá do Sul (SC). Recomenda-se, ainda, que tenha uma abordagem quanto às fibras sustentáveis.

Como contribuição dessa pesquisa, pode-se destacar a discussão teórica acerca da necessidade da inserção de estratégias sustentáveis em empresas têxteis e de confecção. Além disso, essa análise preliminar pode servir de direcionamento sobre a importância das práticas inovadoras sustentáveis e orientar sua adoção no mercado. Por fim, torna-se relevante comentar que a credibilidade da cadeia têxtil, como um todo, tende a ser amplificada se as estratégias em uso se inclinarem para a transparência dos processos. Acredita-se que, com isso, novos estudos e pesquisas podem confirmar, refutar e refletir sobre caminhos e descaminhos sustentáveis no âmbito industrial. 


\section{REFERÊNCIAS}

ABIT. Perfil do Setor: Dados gerais do setor referentes a 2019 (atualizados em dezembro de 2020). Disponível em: https://www.abit.org.br/ cont/perfil-do-setor. Acesso em: 28 jun. 2021.

AUGUSTO, J. S. T. A Dicotomia do Jeans: Símbolo de Moda ou Vilão Ambiental? 2017. 31 f. TCC (Graduação) - Curso de Design de Moda, Universidade do Vale do Taquari, Lajeado, 2017. Disponível em: https://www.univates.br/ bdu/handle/10737/1880. Acesso em: 21 maio 2021.

AVILA, A. P. S. de. Diagnóstico de Trajetórias Empresariais:

Práticas Mais Sustentáveis Relacionadas à Geração de Resíduos Têxteis Sólidos. 2019. 133 f. Dissertação (Mestrado)

- Curso de Pós-Graduação em Moda, Centro de Artes, Universidade do Estado de Santa Catarina, Florianópolis, 2019. Disponível em: https://www.udesc.br/arquivos/ceart/ id_cpmenu/9601/Disserta_o_Ana_Paula_Santos_de_ vila_16232744491203_9601.pdf. Acesso em: 26 maio 2021.

DIAS, R. Modelagem Industrial: Diretrizes para o traçado do molde de calça jeans feminina.

2015. 128 f. Dissertação (Mestrado) - Curso de PósGraduação em Têxtil e Moda, Escola de Artes, Ciências e Humanidades, Universidade de São Paulo, São Paulo, 2015. Disponível em: https://www.teses.usp.br/teses/ disponiveis/100/100133/tde-03062015-202217/publico/ robertodiascorrigida.pdf. Acesso em: 7 jun. 2021.

DUARTE, L. dos S. Estudo Comparativo do Impacto Ambiental do Jeans CO/PET Convencional e de Jeans Reciclado. 2013. 101 f. Dissertação (Mestrado)

- Curso de Pós-Graduação em Engenharia de Produção, Departamento de Engenharia de Produção, Universidade Federal de Minas Gerais, Belo Horizonte, 2013. Disponível em: http://ethicalfashionbrazil.com/ wp-content/uploads/2020/02/disserta_o_luciana_ jeans_final.pdf. Acesso em: 21 maio 2021. 
ELKINGTON, J. Canibais com Garfo e

Faca. São Paulo: M. Books, 1999.

ESTENDER, A. C.; PITTA, T. de T. M. O Conceito do Desenvolvimento Sustentável. Terceiro Setor \&

Gestão, Guarulhos, v. 2, n. 1, p. 22-28, 2008. Disponível em: http://revistas.ung.br/index.php/3setor/article/ view/399/484. Acesso em: 21 maio 2021.

FIGUEIREDO, G. C.; CAVALCANTE, A. L. B. L. Calça Jeans Produtividade e Possibilidades Sustentáveis. Projética, Londrina, v. 1, n. 1, p. 128-145, dez. 2010. Disponível em: https://www.readcube.com/articles/10.5433\%2F22362207.2010v1n1p128. Acesso em: 19 fev. 2021.

FUKUYAMA, F. Trust: the Social Virtues and the Creation of Prosperity. Nova lorque: Free Press, 1995.

GOLDENBERG, M. A Arte de Pesquisar: como fazer pesquisa qualitativa em ciências sociais. 8. ed. Rio de Janeiro: Record, 2004.

GORINI, A. P. F. O segmento de índigo. Banco Nacional de Desenvolvimento Econômico e Social, Rio de Janeiro, $\mathrm{n}$. 10, p. 314-334, set. 1999. Disponível em: https://web.bndes. gov.br/bib/jspui/bitstream/1408/3161/2/BS\%2010\%200\%20 segmento\%20de\%20indigo_P.pdf. Acesso em: 26 maio 2021.

IEMI. Estudo do Mercado Potencial de Jeanswear no

Brasil. 2013. Disponível em: https://www.iemi.com.br/jeanscresce-mais-que-total-de-vestuario/. Acesso em: 7 jun. 2021.

JOSÉ, C. et al. ISO 14.000 - GESTÃO AMBIENTAL. 2014.

Disponível em: http://fait.revista.inf.br/imagens_arquivos/ arquivos_destaque/nKxqWR2dLilrvQz_2014-4-16-14-19-32. pdf. Acesso em: 1 mar. 2021. 
MELLO, L. M. de; CÉSAR, J. B. M. A exploração do trabalho escravo contemporâneo na indústria brasileira da moda. Cadernos Jurídicos da Faculdade de Direito de Sorocaba - São Paulo, v. 1, p. 347-375, 2020. Disponível em: https://www.fadi.br/revista/index.php/ cadernosjuridicos/article/view/63. Acesso em: 5 jul. 2021.

MORITA, A. M. Avaliação de Impactos Ambientais no Setor Têxtil Por Meio da ACV (Avaliação do Ciclo de Vida) Estudo de Caso: Calça Jeans. 2013. 159 f. Tese (Doutorado) - Curso de Pós-Graduação em Engenharia Química, Centro de Tecnologia, Universidade Estadual de Maringá, Maringá, 2013. Disponível em: http://repositorio.uem.br:8080/jspui/ bitstream/1/3687/1/000224297.pdf. Acesso em: 22 dez. 2020.

NARIMATSU, B. M. G. et al. Corantes Naturais Como Alternativa Sustentável na Indústria Têxtil. Valore, Maringá, v. 5, jun. 2020. Disponível em: https://revistavalore.emnuvens. com.br/valore/article/view/507. Acesso em: 19 maio 2021.

DIVYA, R.; MANONMANI, G.; JAYAKUMARI, M. A study on regenerated cellulosic fabrics and its comfort properties. International Journal of Academic Research and Development. p. 218-221. mar. 2018. Disponível em: http://www.academicjournal.in/archives/2018/ vol3/issue3/3-2-98. Acesso em: 7 jun. 2021.

SABINO, M. Dicionário da moda. São Paulo: Campus, 2006.

SALCEDO, E. Moda ética para um futuro sustentável. Barcelona: Gustavo Gili, 2014.

SANTOS, A. C. de J.; SILVA, G. Organização Inovadora Sustentável: Estudo de Caso em Empresa Têxtil. Latin American Journal Of Business Management.

Taubaté, p. 104-111. set. 2018. Disponível em: https://www.lajbm.com.br/index.php/journal/ article/view/559/247. Acesso em: 22 jun. 2021. 
SANTOS, S. Impacto Ambiental Causado pela

Indústria Têxtil. Florianópolis, p. 01-08. mar. 1997.

Disponível em: http://www.abepro.org.br/biblioteca/ enegep1997_t6410.pdf. Acesso em: 22 jun. 2021.

SCHULTE, N. K. Contribuições da Ética Ambiental Biocêntrica e do Veganismo para o Design do Vestuário Sustentável. 2011. 174 f. Tese (Doutorado) - Curso de Pós-Graduação em Design, Artes \& Design, Pontifícia Universidade Católica do Rio de Janeiro, Rio de Janeiro, 2011. Disponível em: https://www.maxwell.vrac.pucrio.br/19116/19116_1.PDF. Acesso em: 22 jun. 2021.

TONIOLLO, M.; ZANCAN, N. P.; WÜST, C. Indústria Têxtil: Sustentabilidade, Impactos e Minimização. In: CONGRESSO BRASILEIRO DE GESTÃO

AMBIENTAL, v. 6., 2015, Porto Alegre, p. 01-05. IBEAS - Instituto Brasileiro de Estudos Ambientais. Disponível em: https://www.ibeas.org.br/congresso/ Trabalhos2015/V-029.pdf. Acesso em: 24 fev. 2021.

VEZZÁ, C. S. B.; COTAIT, P. L. de A.; ALVES, M. A. L. Produção de fibras para confecção de tecidos a partir da reciclagem de pet. In: SIMPÓSIO DE PROJETOS INTEGRADOS EM ENGENHARIA MECÂNICA, 1., 2006, São Paulo. Anais [...]. São Paulo: EPUSP, 2006. p. 01-08. Disponível em: https:// repositorio.usp.br/item/001642220. Acesso em: 1 jul. 2021. 